\title{
La polis literaria: El boom, la Revolución y otras polémicas de la Guerra Fría, de Rafael Rojas (2018), Taurus, $280 \mathrm{p}$.
}

DOI: $10.17230 /$ co-herencia.18.34.15

Rubén López-Cano*

lopezcano@yahoo.com

LaRevolución cubana construyó un poderoso imaginario que atrajo a una gran cantidad de escritores e intelectuales de todo el mundo en un proceso que Iván de la Nuez (2006) denomina "la fantasía roja". Sin embargo, esta adhesión no estuvo exenta de roces y desavenencias. Estas se precipitaron tras el apoyo de Fidel Castro a Escola Superior de Música de Catalunya, España. ORCID: 0000-00019266-5138. la invasión soviética a Checoslovaquia (1968) y el acoso, encarcelamiento y escarnio público al poeta Heberto Padilla (1968-1971). Muchos pensábamos que estos episodios originaron la ruptura del encantamiento hacia el régimen cubano de figuras como Simone de Beauvoir, Jean-Paul Sartre, Susan Sontag, Marguerite Duras, Juan Goytisolo o Carlos Fuentes. Sin embargo, La polis literaria nos muestra que aquellos acontecimientos fueron más bien el punto culminante de una serie de tensiones que se venían acumulando desde el primer contacto entre la intelligentsia mundial y los operadores intelectuales de la isla.

Las discusiones que reconstruye Rojas de aquellas páginas incluyen temas como el deber político del intelectual; la posibilidad de conjugar la estética de la obra de arte autónoma con el compromiso social; la ofensiva de 130 escritores de la isla contra Pablo Neruda y Carlos 
Fuentes por asistir a una reunión del Pen Club en Nueva York; la homosexualidad en Paradiso (1966) de Lezama Lima o el rechazo del marxismo latinoamericano al posestructuralismo francés presente en la crítica literaria de Sarduy. En resumen, un bombardeo discursivo inserto en la difícil tarea de conciliar el compromiso político de los escritores del boom con su legítima aspiración de conquistar los mercados literarios internacionales.

Sin embargo, uno de los mejores aportes de Rojas es su minucioso estudio de la correspondencia de algunos de los escritores estudiados. Si bien epistolarios como los de Julio Cortázar ya estaban publicados desde hace tiempo (Cortázar, 2012), otros permanecían inéditos. En este sentido, es de enorme valor su investigación en archivos especiales de bibliotecas como la Firestone, la Universidad de Princeton y del Harry Ransom Center de la Universidad de Austin. Algunos de ellos parece que solo se han abierto recientemente a la consulta. A lo largo de su investigación, nos enteramos, por ejemplo, de que Carlos Fuentes ideó a principios de 1967 una antología de "relatos sobre dictadores latinoamericanos, para la editorial Gallimard, en París" y que varios de los escritores más representativos del boom se le habían unido. Entre ellos sobresalen Alejo Carpentier, quien no quería escribir sobre Batista; Gabriel García Márquez quien aceptó sin desvelar sobre quién escribiría, y Cortázar que se adhirió "con gran entusiasmo" y prometió "un texto de veinte cuartillas de alusión al cadáver de Eva Perón” (Rojas, 2018, 3441-42). El proyecto nunca llegó a realizarse pero, en opinión del autor, muy probablemente fue el germen de obras del calibre de Yo, el supremo (1974) de Augusto Roa Bastos, El recurso del método (1974) de Alejo Carpentier o El otoño del patriarca (1975) de Gabriel García Márquez.

Esta correspondencia también revela que "Mario Vargas Llosa y Julio Cortázar fueron, tal vez, los dos escritores del boom que más directamente recibieron la presión del aparato político cubano, a través de sus epistolarios con Roberto Fernández Retamar y Haydée Santamaría, directora de Casa de las Américas" (Rojas, 2018, 1593-95). El peruano tuvo una relación muy estrecha con el gobierno cubano cuando se desempeñó (junto con Cortázar) como miembro del consejo colaborador de la revista Casa de las Américas. 
Como tal, viajó continuamente a La Habana donde participó en decisiones editoriales y discusiones intelectuales desde 1962 hasta 1971. En este contexto, Vargas Llosa (de nuevo junto a Cortázar) llegó a pedir la exclusión de Cabrera Infante de las revistas Mundo Nuevo y Libre pensando que "era posible poner de acuerdo a los narradores del boom con la burocracia cultural cubana" (Rojas, 2018, 4019-22). Sin embargo, Carlos Fuentes y Emir Rodríguez Monegal se opusieron de manera tajante. Este episodio es bastante significativo pues, como sabemos, el escritor peruano es desde hace muchos años (ahora sin Cortázar), uno de los más inflexibles críticos del régimen cubano.

De la visión crítica de Rojas quien sale vencedora es la literatura. En efecto, cada autor es analizado en sus propios términos, inscrito en su propia noción de revolución, compromiso político y su propia relación con Cuba. De este modo, el autor evita utilizarlos a manera de armas arrojadizas con las que se les suele atacar a los pro y anticastristas desde el triunfo de la Revolución. Si bien el libro posiciona a sus protagonistas ante hechos, pensamientos y aconteceres concretos, la estrategia argumentativa de Rojas consiste en ceder al lector la posibilidad (y responsabilidad) de cerrar cada silogismo y extraer sus propias conclusiones. De este modo, La polis literaria no condena, simplemente nos permite contemplar de manera crítica las paradojas y fisuras discursivas y políticas de los escritores que ayudaron a construir la subjetividad estética y política de millones de hispanolectores desde los años sesenta hasta nuestros días.

\section{Referencias}

Cortázar, J. (2012). Cartas. Vols. 1-3 (A. Bernárdez y C. Álvarez Garriga, Eds.). Alfaguara.

De la Nuez, I. (2006). Fantasía roja: Los intelectuales de izquierdas y la Revolución cubana. Debate.

Rojas, R. (2018). La polis literaria: El boom, la Revolución y otras polémicas de la Guerra Fría. [Edición Kindle]. Taurus. 